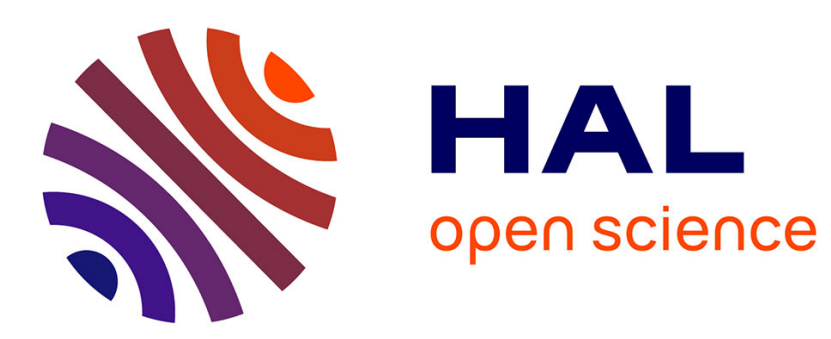

\title{
Evolutions in time and space of laser ablated species by dual-laser photoabsorption spectroscopy
}

\author{
M. Ribiere, Loïc Méès, D. Allano, B.G. Cheron
}

\section{To cite this version:}

M. Ribiere, Loïc Méès, D. Allano, B.G. Cheron. Evolutions in time and space of laser ablated species by dual-laser photoabsorption spectroscopy. Journal of Applied Physics, 2008, 104, pp.043302. 10.1063/1.2960575 . hal-00445039v2

\section{HAL Id: hal-00445039 \\ https://hal.science/hal-00445039v2}

Submitted on 14 Jan 2010

HAL is a multi-disciplinary open access archive for the deposit and dissemination of scientific research documents, whether they are published or not. The documents may come from teaching and research institutions in France or abroad, or from public or private research centers.
L'archive ouverte pluridisciplinaire HAL, est destinée au dépôt et à la diffusion de documents scientifiques de niveau recherche, publiés ou non, émanant des établissements d'enseignement et de recherche français ou étrangers, des laboratoires publics ou privés. 


\title{
Evolutions in time and space of laser ablated species by dual-laser photo-absorption spectroscopy
}

\author{
M. Ribière, L. Méès, D. Allano and B. G. Chéron \\ UMR CNRS 6614, CORIA \\ Technopôle du Madrillet, BP 12 \\ 76801 Saint Etienne du Rouvray \\ FRANCE \\ ribiere@coria.fr, cheron@coria.fr
}

\begin{abstract}
An atmospheric aluminum laser induced plasma is investigated by means of absorption and emission spectroscopy in the near ultraviolet range. The absorbed radiation is produced by a second aluminum laser induced plasma which is generated at adjustable time delay. The measurement of both ground and resonant state number densities are derived from the fitting of the experimental $308.21\left({ }^{2} P^{\circ}{ }_{1 / 2}-{ }^{2} D_{3 / 2}\right)$ and $396.15 \mathrm{~nm}\left({ }^{2} P_{3 / 2}^{\circ}-{ }^{2} S_{1 / 2}\right)$ line absorption profiles on the numerical solution of the radiative transfer equation (RTE). Owing to the dominant role played by the Stark effect in the line broadening and shifting, the calculation also provides the evolution in time and in space of the free electron density along the line of sight. More classically, the same method is applied to the emission profiles which exhibit strong self absorbed shapes. The reliability of the results derived from both absorption and emission experiments is analysed and the origin of the asymmetric shape of the absorption lines is discussed.
\end{abstract}

\section{INTRODUCTION}

Laser induced plasma spectroscopy (LIPS) consists in analyzing the radiation which is emitted when a laser pulse is focused onto a target. ${ }^{1}$ The available power density in the focus area of a nanosecond Q-switched laser is generally high enough to evaporate solid surface ${ }^{2,3}$ and to ionize the ejected vapor through multi-photon absorption and inverse bremsstrahlung processes. ${ }^{4,5}$ Two theoretical approaches of the plasma expansion are currently developed: the fluid-dynamic one, ${ }^{6-8}$ which consists in the resolution of the three-dimensional NavierStokes equations, and the microscopic one, which is based on the Monte Carlo method. ${ }^{9,10}$ The laser induced plasmas are used to perform thin film deposition ${ }^{11,12}$ and to form nanoparticles. ${ }^{13,14}$ The control of these processes requires the knowledge of the plasma plume expansion dynamic and of the chemical kinetics ${ }^{15,16}$ of the reactions arising between the plasma species and the ambient gas. The LIPS technique has been also widely applied to the determination of the composition of solid or liquid samples ${ }^{17-20}$ : Gomba et al. ${ }^{18}$ have derived $\mathrm{Li}$ concentrations in $\mathrm{Al}-\mathrm{Li}$ alloys from the intensity ratio of different optically thin lines. They assume that the ionic and atomic excited state number densities are linked to each other through Boltzmann and Saha equations. Vieitez et $a .^{20}$ have directly derived the concentration of copper in scrap metals from calibration curves.

However, the emission spectroscopy provides data which only concern the excited states of the plasma species. In LIPS experiments, the temperature is around ten thousand Kelvins. ${ }^{21}$ Consequently, the ground state of an atom is roughly one hundred times more populated than the first excited level if we suppose that its energy is equal to $4 \mathrm{eV}$. The studies devoted to the experimental measurement of the ground state density of the ablated particles in LIPS experiments are based on the analysis of self-reversed resonant lines: Hermann et al. ${ }^{22}$ have deduced Ti(II) number densities from a two-zone model. Sakka et al. ${ }^{23,24}$ and Karabourniotis ${ }^{25}$ has measured the density of metallic species by solving the RTE using different relative distribution functions. They have pointed out that the temperature gradient at the border of the plasma has a strong influence on the recorded line profile. In the model developed by Sakka et al., ${ }^{23}$ the densities are supposed to have Gaussian distributions.

Nevertheless, the determination of the ground state density from self-reversed lines strongly depends on both line characteristics and experimental conditions. Moreover, in LIPS experiments, these densities cannot be estimated over a large time scale because the resonant lines become rapidly optically thin on account of the fast diffusion of the plume. An absorption experiment could at once overcome these difficulties and lead to reliable atomic density measurements. The required radiation source must be spectrally broadened and its intensity must be at least one order of magnitude higher than the one of the probed plasma.

At the early moments after the laser pulse, it is well known ${ }^{26}$ that the plasma radiates a bright continuum owing to free-free and free-bound transitions. This emission has been used by Costello et al. ${ }^{27-29}$ in the purpose of performing dual-laser photo-absorption experiments in the vacuum ultraviolet and extreme ultraviolet spectral regions: a first $\mathrm{Q}$-switched laser generates the plasma to 
be investigated while a time delayed second laser creates the continuum source.

In this paper, we report a near ultraviolet dual-laser absorption spectroscopy experiment. The target is an aluminum sample. The RTE is solved using the assumptions of the Sakka model ${ }^{23}$ in the purpose of simulating the absorption profiles of the $\mathrm{Al}(\mathrm{I}) 308.21 \mathrm{~nm}$ $\left({ }^{2} P^{\circ}{ }_{1 / 2}{ }^{2} D_{3 / 2}\right)$ and $396.15 \mathrm{~nm}\left({ }^{2} P^{\circ}{ }_{3 / 2^{-}}{ }^{2} S_{1 / 2}\right)$ lines. The time evolution of the density distributions in the core of the plasma is presented. The reliability of the method, as well as the influence of the different assumptions of the model on the recorded line shapes are discussed.

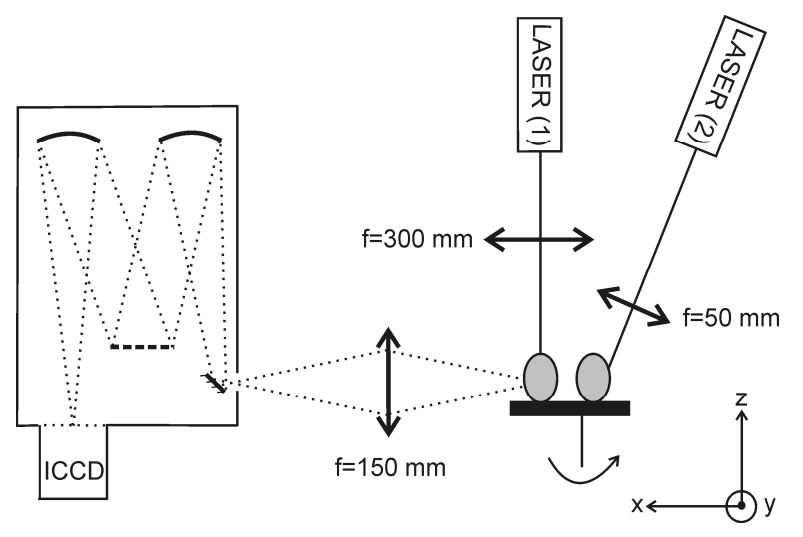

Fig. 1: Experimental Set-up.

\section{EXPERIMENT} Fig. 1.

The schematic of the experimental set-up is given in

The second harmonic of a Q-switched Nd:YAG (yttrium aluminum garnet) laser (pulse duration $4 \mathrm{~ns}$, energy 65 $\mathrm{mJ}$ ) is focused onto a rotating aluminum alloy disk (Al: $95 \%$, Cu: $4.5 \%, \mathrm{Mg}$ and Si: $0.5 \%$ ) by using a $30 \mathrm{~cm}$ focal length lens. The atmospheric plasma created by the laser pulses is analyzed by means of absorption spectroscopy. Subsequently, this plasma will be called "plasma 1" in this paper.

The required emission source for absorption is another atmospheric laser induced aluminum plasma which is created by focusing on the target a second double frequency Q-switched Nd:YAG laser (pulse duration $10 \mathrm{~ns}$, energy $100 \mathrm{~mJ}$ ) by using a $5 \mathrm{~cm}$ focal length lens. This plasma, which produces a bright and broadband emission in the near ultraviolet, will be called "plasma 2". These plasmas are about one centimeter apart. The synchronization of the lasers is controlled by a pulse/delay generator and the delay between the laser pulses $\left(t_{d}\right)$ can be adjusted between 1 and $5 \mu$ s.

The "plasma 1" plume is imaged onto the entrance slit of a Czerny-Turner spectrometer by a bi-convex quartz lens (focal length $15 \mathrm{~cm}$ ) with a 1:1 magnification. The spectrometer (focal length $75 \mathrm{~cm}$ ) is equipped with a 1800 grooves $\mathrm{mm}^{-1}$ grating. The entrance slit width, which limits the spatial resolution along the $z$ axis direction, is fixed at
$50 \mu \mathrm{m}$. The spectral resolution is equal to $0.04 \mathrm{~nm}$. Acquisitions are performed by using an intensified charge coupled device camera (ICCD). The pixel height $(24 \mu \mathrm{m})$ is equal to the spatial resolution along the y axis direction. The recording of the isolated $312.56 \mathrm{~nm} \mathrm{Hg}$ line reveals that the apparatus function profile of the spectrometer can be fairly adjusted on a Gaussian shape. The time gate and the time delay between the laser pulse which creates the "plasma 2" and the beginning of the acquisition are fixed at 50 ns and 25 ns respectively. The ICCD signals are conversed into spectral intensity units $\left(\mathrm{W} / \mathrm{m}^{2} / \mathrm{sr} / \mathrm{nm}\right)$ by using a calibrated tungsten ribbon lamp.

\section{THEORETICAL BACKGROUND}

The radiative transfer equation describes how the spectral intensity $I(x, \lambda)$ of a transition changes along a direction $x$ through an absorbing and emitting medium:

$$
\begin{aligned}
\frac{d I(x, \lambda)}{d x} & =\frac{f(x, \lambda)}{\int_{0}^{\infty} f(x, \lambda) d \lambda}\left\{n_{u}(x) \frac{h c}{\lambda_{u l}} \frac{A_{u l}}{4 \pi}\right. \\
& \left.-\frac{h \lambda_{u l}}{c}\left[n_{l}(x) B_{l u}-n_{u}(x) B_{u l}\right] I(x, \lambda)\right\}
\end{aligned}
$$

where $n_{l}(x)$ and $n_{u}(x)$ are respectively the number densities of the lower and upper levels of this transition and $\lambda_{u l}$ its central wavelength. The Einstein coefficients $A_{u l}, B_{u l}$ and $B_{l u}$ are linked to each other by the classical relations:

$$
\begin{gathered}
A_{u l}=\frac{8 \pi h}{\lambda^{3}} B_{u l}, \\
\frac{B_{u l}}{B_{l u}}=\frac{g_{l}}{g_{u}},
\end{gathered}
$$

$g_{u}$ and $g_{l}$ are the degeneracies of the lower and upper levels of the transition. The ratio:

$$
P(\lambda, x)=\frac{f(x, \lambda)}{\int_{0}^{\infty} f(x, \lambda) d \lambda}
$$

is the normalized form of the $f(x, \lambda)$ line profile.

In laser induced plasma experiments, the line profiles are mainly broadened by Stark effects ${ }^{30-32}$ due to the electron collisions (and ion collisions in less importance) which lead to Lorentzian line shapes:

$$
f(x, \lambda)=\frac{1}{1+4\left(\frac{\lambda-\lambda_{u l}-\Delta \lambda_{\text {shift }}(x)}{\Delta \lambda_{\text {width }}(x)}\right)^{2}}
$$

Neglecting the ion effects, the Stark width and shift may be regarded as linearly dependent on the electron density according to:

$$
\begin{gathered}
\Delta \lambda_{\text {width }}(x)=w n_{e}(x), \\
\Delta \lambda_{\text {shift }}(x)=d n_{e}(x),
\end{gathered}
$$


The $w$ and $d$ coefficients have been tabulated by Griem. ${ }^{30}$ In our calculations, we neglect their slight dependence on the temperature.

The calculation of the spectral intensity emerging from a laser induced plasma requires to hypothesize about the spatial distribution of the involved $n_{u}(x), n_{l}(x)$ and $n_{e}(x)$ number densities along the line of sight. For instance, Hermann et al. ${ }^{22}$ have simulated self-absorbed $\mathrm{Ti}(\mathrm{II})$ lines from the division of the investigated medium into two isothermal zones: the central zone which is the plasma itself and the peripheral region which contains the neutral metallic vapor. Sakka et al.. ${ }^{23}$ have assumed Gaussian distributions, according to plasma plume lateral images. In a previous work $^{33,34}$ we have shown that aluminum selfreversed lines can be fairly simulated by using trapezoidal distributions. Karabourniotis ${ }^{25}$ has also obtained reliable results from original functions depending on different "shape factors". Generally speaking, these works show that the fitting of the numerical integration of the RTE on the experimental spectra is not strongly affected by the shape of the selected spatial distributions.

According to the Sakka's model, ${ }^{23}$ we assume Gaussian profiles:

$$
n_{i}(x)=n_{i 0} \exp -\left(4 \ln 2 \frac{x^{2}}{\sigma_{i}^{2}}\right)
$$

where the subscript $i=e, l$ and $u$ stands for electrons, and lower and upper state number densities respectively. Owing to the major role played by the electron collisions in the atomic excitation, the electron full width at half maximum (FWHM) parameter is supposed to be equal to the upper level one:

$$
\sigma_{e}=\sigma_{u}
$$

The excitation temperature of the considered transition is defined by the following relation:

$$
T_{u l}=\frac{E_{u}-E_{l}}{k \ln \left[\frac{g_{u} n_{l}}{g_{l} n_{u}}\right]}
$$

where $E_{u}$ and $E_{l}$ are respectively the energies of the lower and upper levels of the transition. $k$ is the Boltzmann constant. In laser induced plasmas, this temperature is decreasing when moving from the core to the edge of the plasma. Consequently, the resonant lines are self reversed and the ratio $r=\sigma_{l} / \sigma_{u}$ of the width parameters is greater than one. Sakka et al. ${ }^{23}$ have shown that the value of this ratio strongly influences the depth of the selfreversal lines. In the case of aluminum laser induced plasmas, ${ }^{24}$ this parameter is found to vary between 1 and 3 during the expansion phase of the plasma.

The integration of the RTE requires to determine the plasma plume width $\Delta x$ along the line of sight. At any moment, the plasma is supposed to be cylindrically symmetric $^{35}$ along the axis $\mathrm{Oz}$ normal to the target. In our optical conditions, the height $\Delta y$ of the image formed on the ICCD is equal to the diameter of the aluminum plasma.
This image is representative of the excited region of the plasma. Hence, we can write:

$$
\Delta x=\Delta y \approx 2 \sigma_{u}
$$

Four parameters govern the calculation: the $n_{e 0}, n_{u 0}$ and $n_{10}$ maximum densities at $\mathrm{x}=0$ and the $\sigma_{l}$ parameter width of the metallic vapor. When working in emission, the boundary condition for the RTE integration is obviously: $I\left(x=-2 \sigma_{l}, \lambda\right)=0$. Plasma 2 , which is the radiation source of our dual-laser photo-absorption experiments, produces a spectrum which cannot be considered as uniform in the few nanometer range of interest. So, we have separately recorded this spectrum and its intensity has been developed in a polynomial form in the purpose of determining the adequate boundary condition of the RTE. The last step of the calculation achieves the convolution of the intensity at the exit of the plasma, i. e. $I\left(x=+2 \sigma_{l}, \lambda\right)$ by the Gaussian apparatus function (FWHM $\approx 0.04 \mathrm{~nm}$ ) of the spectrometer.

\section{RESULTS}

The experiments have been performed on a target surface fixed at the distance $z=0.9 \mathrm{~mm}$ from the $O x$ optical axis. This choice has been governed, on the one hand, by the production of self-reversed emission lines by the "plasma 1" and, on the other hand, by the strong intensity of the continuum yielded by the "plasma 2" at the same position. Therefore, the ground state density distribution has been carried out from both emission spectroscopy and absorption spectroscopy. That will make possible the comparison between these methods, which is presented in section $\mathrm{V}$.

When the delay between the laser pulses is greater than $1.6 \mu \mathrm{s}$, the intensity of the continuum is one order of magnitude higher than the line emission one. In these conditions, the emission term plays a negligible role in the integration of the RTE. Experimental absorption spectra of the $308.21 \mathrm{~nm}$ line are plotted in Fig. 2, with the corresponding results of our calculations. The configuration and the energy of the involved levels are respectively ${ }^{2} D_{3 / 2}$ and $4.022 \mathrm{eV}$ for the upper level and ${ }^{2} \mathrm{P}_{1 / 2}^{\circ}$ and $0 \mathrm{eV}$ for the lower one. The spectral broadening and the absorption hollow depth of this transition are decreasing with increasing delay, according to both electron recombination and species diffusion. ${ }^{21,36}$

We present in Fig. 3 the absorption spectra of another $\mathrm{Al}(\mathrm{I})$ resonant line located at $396.15 \mathrm{~nm}$. The configuration and the energy of the involved levels are respectively ${ }^{2} S_{1 / 2}$ and $3.143 \mathrm{eV}$ for the upper level and ${ }^{2} P^{\circ}{ }_{3 / 2}$ and $0.014 \mathrm{eV}$ for the lower one. The decrease of the hollow depth with increasing time is slightly less pronounced than in the $308.21 \mathrm{~nm}$ line case. In fact, this weak variation is due to the simultaneous decreases of both upper and lower level populations.

The dual-laser photo-absorption spectroscopy has been applied to the $\mathrm{Al}(\mathrm{I}) 308.21 \mathrm{~nm}$ and $396.15 \mathrm{~nm}$ transitions for time delays varying from 1 to $5 \mu \mathrm{s}$. The 
relevant fitting procedures lead to the time evolutions of the electron density $\left(n_{e 0}\right)$, lower state density $\left(n_{10}\right)$ and excitation temperature $\left(T_{u l}\right)$ at the centre of the plasma which are displayed in Fig. 4 and 5. Generally speaking, the absorption experiments (full triangles) provide more regular time evolutions than the ones deduced from the emission ones (open squares).
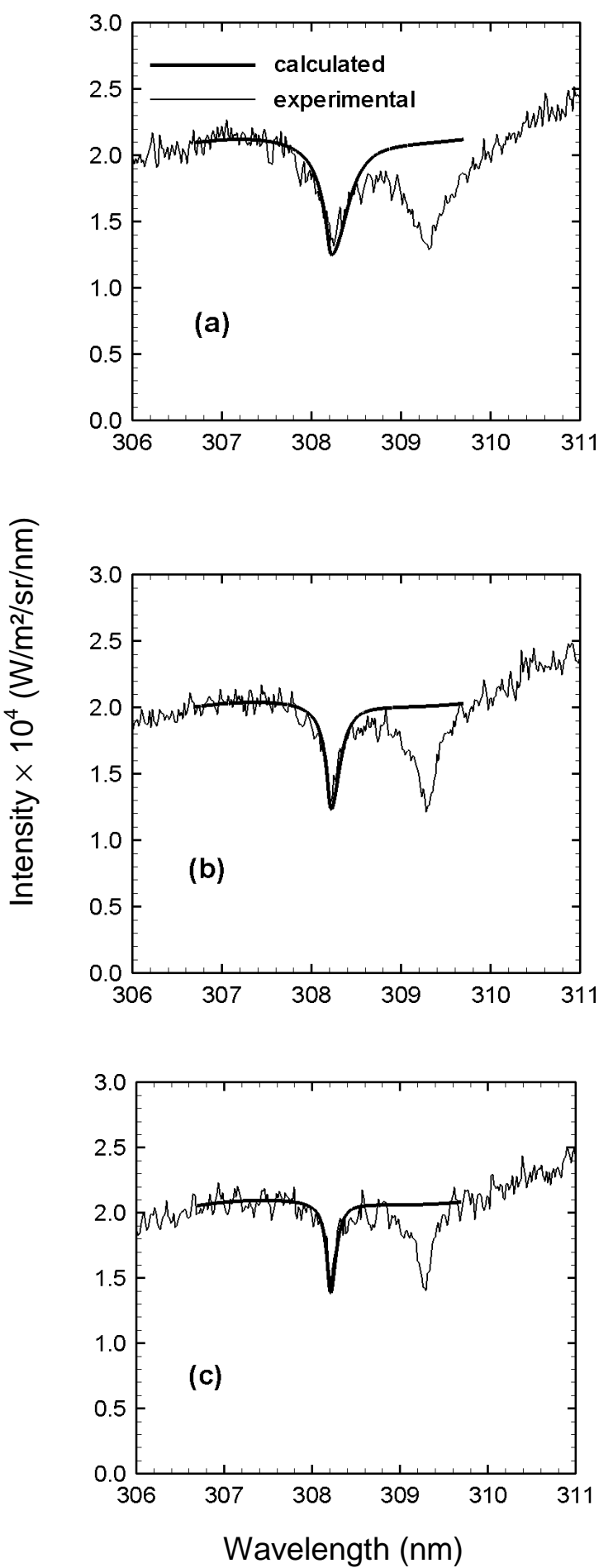

Fig. 2: Absorption spectra of the $308.21 \mathrm{~nm}$ transition at different delays between the laser pulses: (a) $\mathrm{t}_{\mathrm{d}}=1 \mu \mathrm{s}$, (b) $2.4 \mu \mathrm{s}$, (c) $4 \mu \mathrm{s}$. Thin lines correspond to the experimental spectra while thick lines result from our calculation
The measured density of the aluminum ground states $\left({ }^{2} P^{\circ}{ }_{1 / 2}\right.$ and ${ }^{2} P_{3 / 2}^{\circ}$ doublet $)$ are in a ratio of two, according to the value of their respective statistical weights and to the tiny energetic gap between them $(0.014 \mathrm{eV})$.
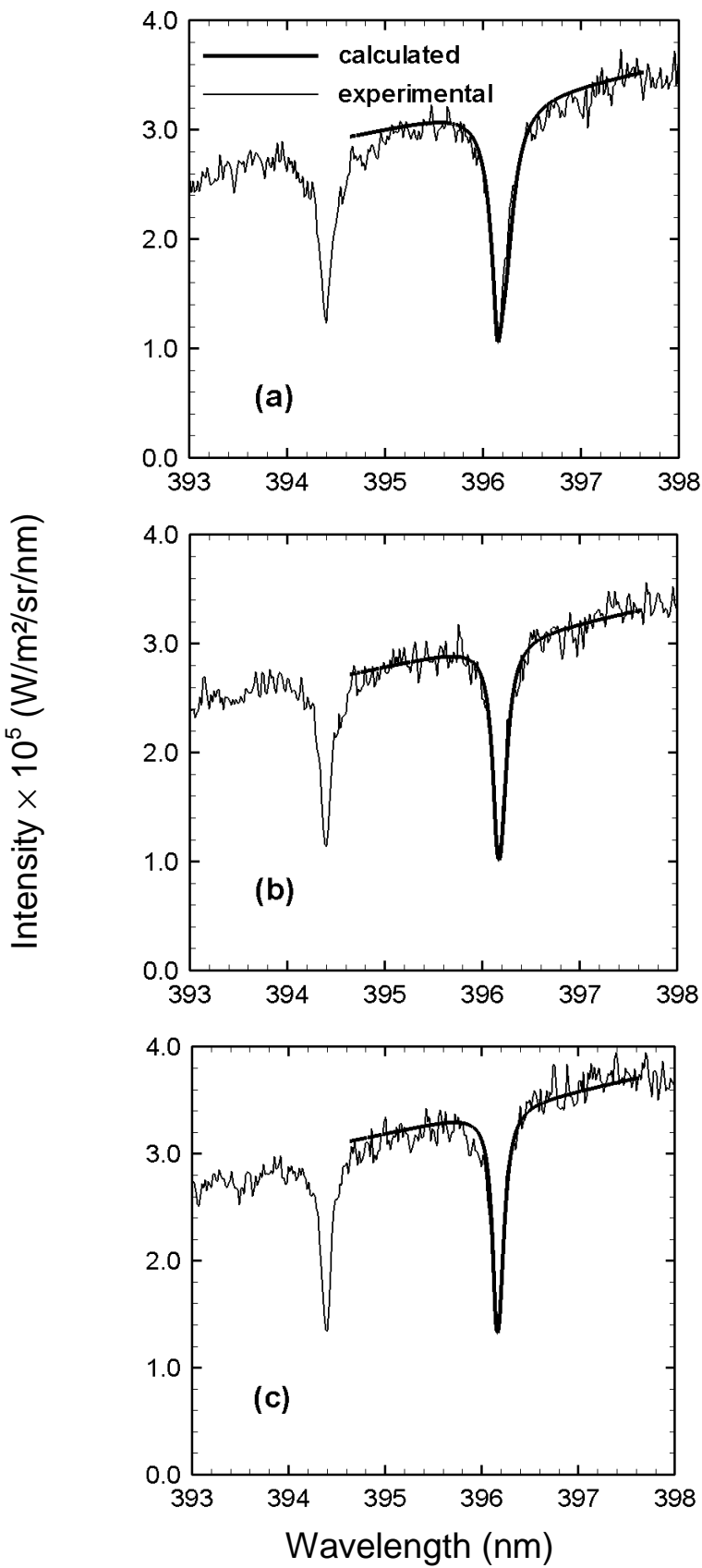

Fig. 3: Absorption spectra of the $396.15 \mathrm{~nm}$ transition at different delays between the laser pulses. (a) $t_{d}=1.3 \mu \mathrm{s}$, (b) $3 \mu \mathrm{s}$, (c) $5 \mu \mathrm{s}$. Thin lines correspond to the experimental spectra while thick lines result from our calculation

The electron density $\left((4 \pm 1) 10^{23} \mathrm{~m}^{-3}\right.$ at $\left.\mathrm{t}_{\mathrm{d}}=1 \mu \mathrm{s}\right)$ is two orders of magnitude greater than the atomic one. The plasma core is hence fully ionized. As a matter of fact, numerous $\mathrm{Al}(\mathrm{II})$ bright spectral lines (281.62 nm, 466.30 $\mathrm{nm}, 559.33 \mathrm{~nm} . .$.$) are present in the recorded spectra.$ The hypothesis of dominant Stark broadenings is then strongly strengthened. 
Over the whole acquisition time range, the results of the fitting procedure point out a clear discrepancy between the ${ }^{2} S_{1 / 2}$ and ${ }^{2} D_{3 / 2}$ excitation temperatures: for instance, at $t_{d}=1.5 \mu \mathrm{s}$, the former one is equal to $8000 \mathrm{~K}$ when it is only $5000 \mathrm{~K}$ for the latter one. The corresponding overpopulation of the ${ }^{2} S_{1 / 2}$ level as compared to the ${ }^{2} D_{3 / 2}$ one cannot be ascribed to the uncertainties related to our experiments and calculations. It means clearly that the laser induced plasma state is strongly out of equilibrium during its relaxation phase.
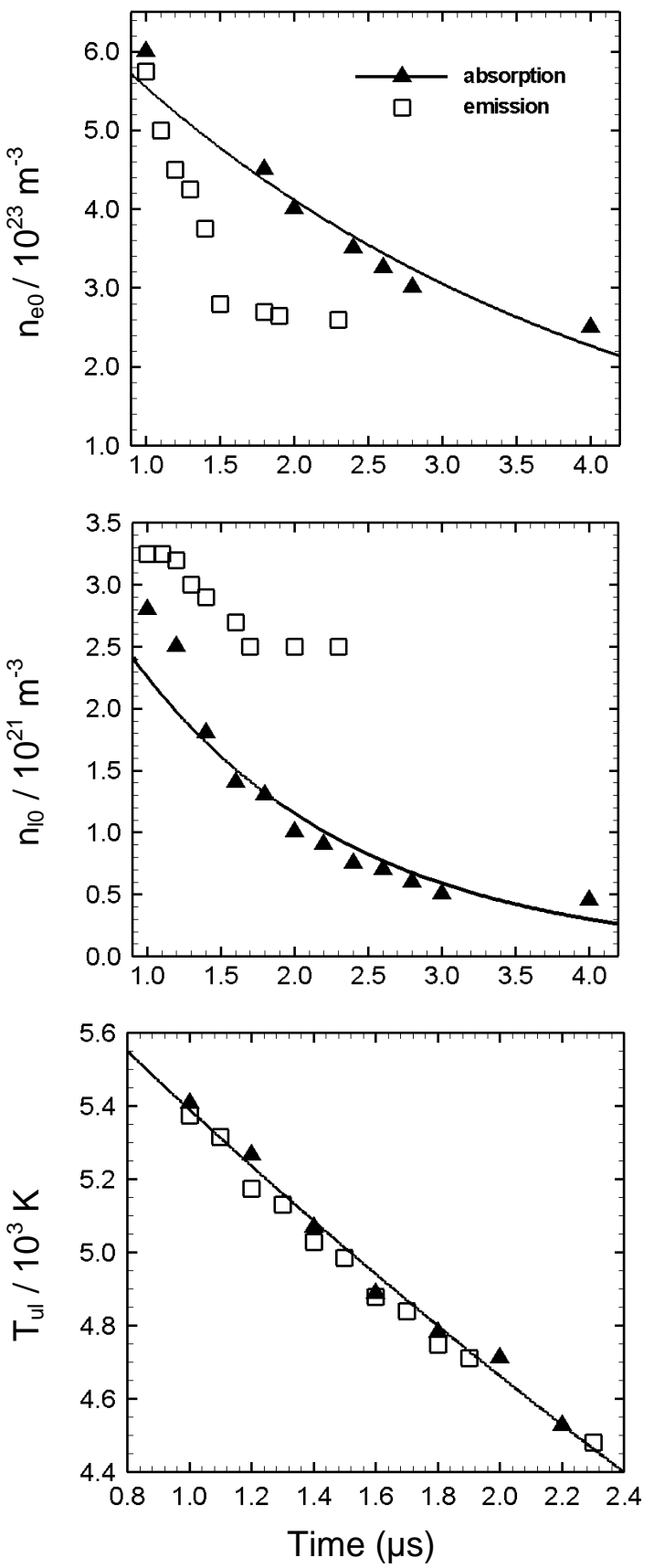

Fig. 4: Time evolutions: electron, lower level densities, and excitation temperature of the $308.21 \mathrm{~nm} \mathrm{Al}(\mathrm{I})$ transition at the center of the plasma. Full triangles represent the dual photo-absorption fittings while open squares refer to the emission ones.
The time evolution of the measured densities can be roughly fitted on decreasing exponential functions the characteristic times of which are given in Table I. These values are derived from absorption experiments. They are within the same order of magnitude and are linked at once to the chemical and to the aerodynamic relaxation times of the ablated matter. Comparable but less reliable times can be obtained from emission spectroscopy. This point will be discussed in the next section.
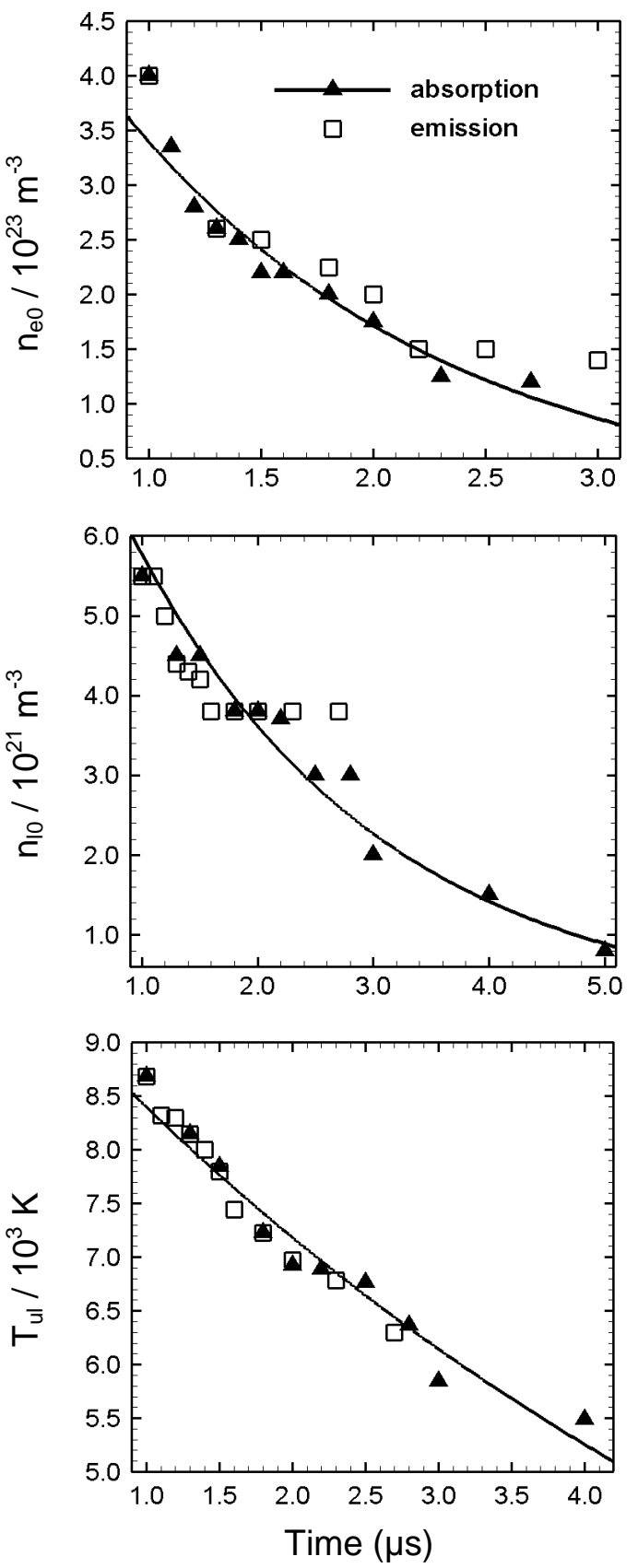

Fig. 5: Time evolutions: electron, lower level densities, and excitation temperature of the $396.15 \mathrm{~nm} \mathrm{Al}(\mathrm{I})$ transition at the center of the plasma. Full triangles represent the dual photo-absorption fittings while open squares refer to the emission ones.

According to the arguments presented in section III, the fitting procedure leads to $r$ ratios which are greater 
than one: $r=1.3$ (emission), and $r=1.05$ (absorption) for the $308.21 \mathrm{~nm}$ line, and $\mathrm{r}=2.3$ (emission) and $\mathrm{r}=1.5$ (absorption) for the $396.15 \mathrm{~nm}$ line, respectively. It is important to note that these values are almost constant during the investigated time range. The time evolutions of the atomic width parameters are displayed in Fig. 6: for instance, $\sigma_{u}$ varies between $1.2 \mathrm{~mm}$ at $t_{d}=1 \mu$ s to $1.9 \mathrm{~mm}$ at $t_{d}=5 \mu \mathrm{s}$. These parameters evolve according to power laws $\left(\sim \mathrm{t}^{0.27}\right)$ which are close to the ideal blast wave Sedov-Taylor law ${ }^{37}\left(\sim \mathrm{t}^{2 / 5}\right)$.

Fig. 7 shows the emission profiles of the $308.21 \mathrm{~nm}$ and $396.15 \mathrm{~nm}$ lines (the experiments are therefore carried out without the "plasma 2"). The delay time between the laser trigging and the acquisition is fixed at $1.3 \mu \mathrm{s}$. The self-absorption is more pronounced for the $396.15 \mathrm{~nm}$ transition than for the $308.21 \mathrm{~nm}$ one. This remark also applies to the absorption profiles. This is mainly due to the values of the involved atomic parameters (Einstein coefficients and statistical weights) on the one hand, and to the strong variation of the ICCD detector sensitivity between these wavelengths on the other hand. Therefore the fitting procedure is expected to provide an estimation of the ${ }^{2} P^{\circ}{ }_{3 / 2}$ level number density which is more precise than the ${ }^{2} P^{\circ}{ }_{1 / 2}$ one.

\section{DISCUSSION}

At first, it is important to emphasize that the standard departure between all the experimental and the simulated line spectra that we have investigated, in emission and in absorption, is less than $1 \%$. In order to examine the influence of the different parameters involved in the integration of the RTE, we adopt the following procedure: starting from the Table II which presents the set of data that yields the best fit of the $396.15 \mathrm{~nm}$ line at $t_{d}=1.3 \mu \mathrm{s}$ after the creation of the "plasma 1", we change one among these values (successively $n_{u 0}, n_{e 0}, n_{10}$ and $\sigma_{l}$ ) by a factor $30 \%$ and we solve again the RTE.

TABLE I. Characteristic decrease time of the electron, upper and lower level densities (from $\mathrm{Al}(\mathrm{I})$ absorption line at $396.15 \mathrm{~nm}$ )

\begin{tabular}{cc}
\hline Plasma parameter & Characteristic time \\
\hline Electron density $n_{e 0}$ & $\tau_{\mathrm{e}}=1.60 \mu \mathrm{s}$ \\
Upper level density $n_{u 0}$ & $\tau_{\mathrm{u}}=0.79 \mu \mathrm{s}$ \\
Lower level density $n_{l 0}$ & $\tau_{1}=2.14 \mu \mathrm{s}$ \\
\hline \hline
\end{tabular}

The results are then compared to the original one by the means of two parameters: the normalized average departure Err and its maximum value Max(Err):

$$
\begin{gathered}
\operatorname{Err}=\sqrt{\frac{1}{N} \sum_{i}\left|\frac{I_{\exp }\left(\lambda_{i}\right)-I\left(\lambda_{i}\right)}{I_{\exp }\left(\lambda_{i}\right)}\right|^{2}} \\
\operatorname{Max}(\operatorname{Err})=\operatorname{Max}\left|\frac{I_{\exp }\left(\lambda_{i}\right)-I\left(\lambda_{i}\right)}{I_{\exp }\left(\lambda_{i}\right)}\right|
\end{gathered}
$$

$I_{\exp }(\lambda)$ is the original spectral intensity (best fit) and $I(\lambda)$ is the new one (one parameter have been changed by a factor $30 \%$ ). $N$ is the discrete number of points which are involved in the simulation of the line profile. Each point corresponds to a wavelength $\lambda_{i}$. The results are displayed in Table III.

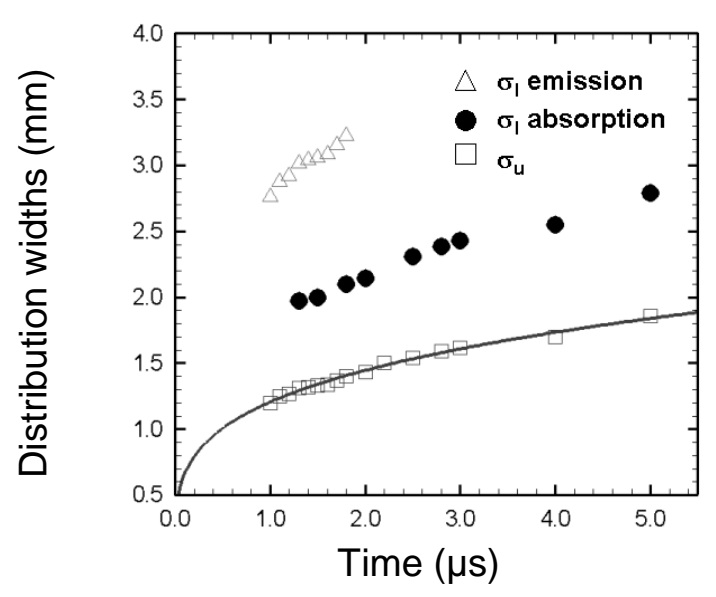

FIG. 6: Time evolution of the distribution widths. Open squares represent $\sigma_{\mathrm{u}}$ (measured), while open triangles and full circles represent $\sigma_{\mathrm{l}}$ (adjusted).
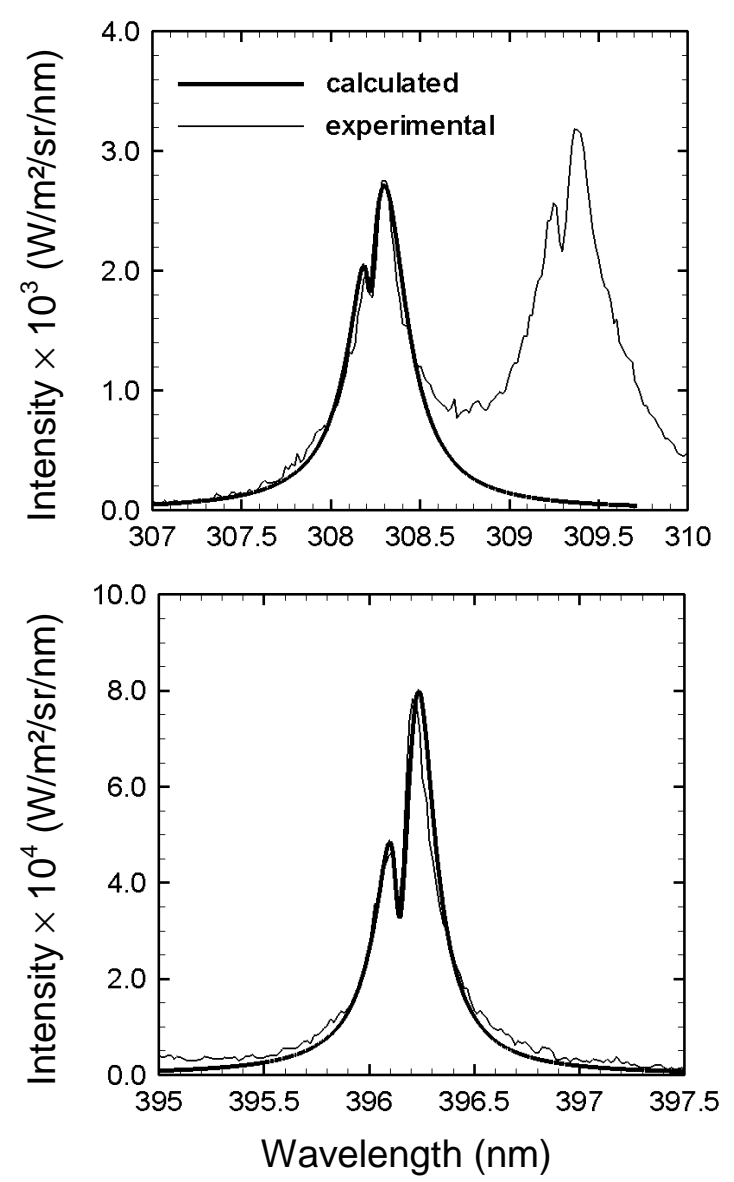

FIG. 7: Emission spectra of the $308.21 \mathrm{~nm}$ and $396.15 \mathrm{~nm}$ transitions at $\mathrm{t}_{\mathrm{d}}=1.3 \mu \mathrm{s}$. Thin lines correspond to the experimental spectra while thick lines result from our calculations 
Concerning the emission profiles, the simulation is very sensitive to a variation of $n_{u 0}$ and $n_{e 0}$ densities. The former one directly influences the intensity of the line whereas the latter one generates the distortion of its shape through Stark width and shift. So, the totality of the line is clearly changed when these parameters are modified, leading to large numerical errors. The absorption lines exhibit much more regular shape than the emission ones and are therefore less sensitive to variation of $n_{u 0}$ and $n_{e 0}$ densities.

The numerical average departures calculated for $n_{10}$ and $\sigma_{l}$ are roughly the same whatever simulated lines (emission or absorption). However, the determination of the $\mathrm{Al}(\mathrm{I})$ ground state density is directly linked to the depth and width of the hole of the self reserved $396.15 \mathrm{~nm}$ line and is therefore essentially dependent on the instrumental resolution. $^{23}$ In our experimental conditions, only few pixels (less than 6) are concerned by this particular spectral range. Consequently, a lack of precision about the apparatus function has a great influence on the $n_{10}$ and $\sigma_{\mid}$determination from the simulation of the self-reversed lines. This argument gives a serious advantage to the absorption experiments which provide more regular lines spreading on larger spectral ranges (more than 50 pixels).

TABLE II. Species densities and width parameters deduced from the $396.15 \mathrm{~nm}$ line $(\mathrm{td}=1.3 \mu \mathrm{s})$.

\begin{tabular}{lcc}
\hline \hline & Emission & Absorption \\
\hline Electron density $\left(10^{23} \mathrm{~m}^{-3}\right)$ & 2.6 & 2.6 \\
Lower level density $\left(10^{21} \mathrm{~m}^{-3}\right)$ & 5.0 & 4.5 \\
Upper level density $\left(10^{19} \mathrm{~m}^{-3}\right)$ & 2.8 & 2.5 \\
Excitation temperature $(\mathrm{kK})$ & 8.1 & 8.1 \\
$\sigma_{u}=\sigma_{e}\left(10^{-3} \mathrm{~m}\right)$ & 1.3 & 1.3 \\
$\sigma_{l}\left(10^{-3} \mathrm{~m}\right)$ & 3.0 & 2.0 \\
\hline \hline
\end{tabular}

In the purpose of illustrating the influence of the apparatus function, we display in Fig. 8 the convoluted and deconvoluted profiles of the $396.15 \mathrm{~nm}$ line and we calculate the normalized average departure defined by:

$$
\operatorname{ErrConv}=\sqrt{\frac{1}{N} \sum_{i}\left|\frac{I_{\text {conv }}\left(\lambda_{i}\right)-I_{\text {deconv }}\left(\lambda_{i}\right)}{I_{\text {conv }}\left(\lambda_{i}\right)}\right|^{2}}
$$

In emission, the convolution yields a flattening of the profile which is clearly stronger than in absorption. The average departure is $17 \%$ in the former case whereas it is only $8 \%$ in the latter one.

TABLE III : Sensitivity of the method: each varying parameter is increased by a factor $30 \%$.

\begin{tabular}{ccccc}
\hline \hline Varying parameter & \multicolumn{2}{c}{ Absorption } & \multicolumn{2}{c}{ Emission } \\
\hline & Err & $\operatorname{Max}($ Err $)$ & Err & $\operatorname{Max}($ Err $)$ \\
$n_{u 0}$ & $4 \%$ & $20 \%$ & $30 \%$ & $30 \%$ \\
$n_{e 0}$ & $2 \%$ & $13 \%$ & $26 \%$ & $36 \%$ \\
$n_{l 0}$ & $6 \%$ & $21 \%$ & $7 \%$ & $28 \%$ \\
$\sigma_{l}$ & $4 \%$ & $18 \%$ & $3 \%$ & $16 \%$ \\
\hline \hline
\end{tabular}

These results bring proof of the high reliability of the absorption experiments that we have carried out as compared to the standard emission ones. This statement is fully supported by the time evolutions of the excitation temperature and species densities which are presented in Fig. 4 and 5: whatever regarded parameter, the plots derived from absorption are much more regular than the emission ones. Previous works ${ }^{24}$ carried out on aluminum in low pressure conditions have actually exhibited large uncertainties in the time evolution of the plasma parameters calculated from emission spectroscopy.

Another advantage of the dual-laser photo-absorption spectroscopy must be emphasized: during the first moments of the relaxation of the plasma, the species densities can be derived from both emission and absorption. After two microseconds, the hole in the selfreversed resonant lines disappears, and absorption becomes the one method able to follow the evolution of the plasma, as shown in Fig 4 and Fig. 5.

Considering all the parameters which influence the results of the fitting procedure, we estimate that, at any time, the width parameters $\left(\sigma_{l}\right.$ and $\left.\sigma_{u}=\sigma_{e}\right)$ and the aluminum ground state and electron densities $\left(n_{l}\right.$ and $\left.n_{e}\right)$ are determined with an accuracy which is better than $10 \%$, and $30 \%$, respectively.

In the remaining part of this section, we investigate the influence of the $n_{40}, n_{10}$ and $n_{e 0}$ species densities on the absorption line shapes. At the entrance of the spectrometer (i.e. before convolution) they are clearly asymmetric (see Fig 8).
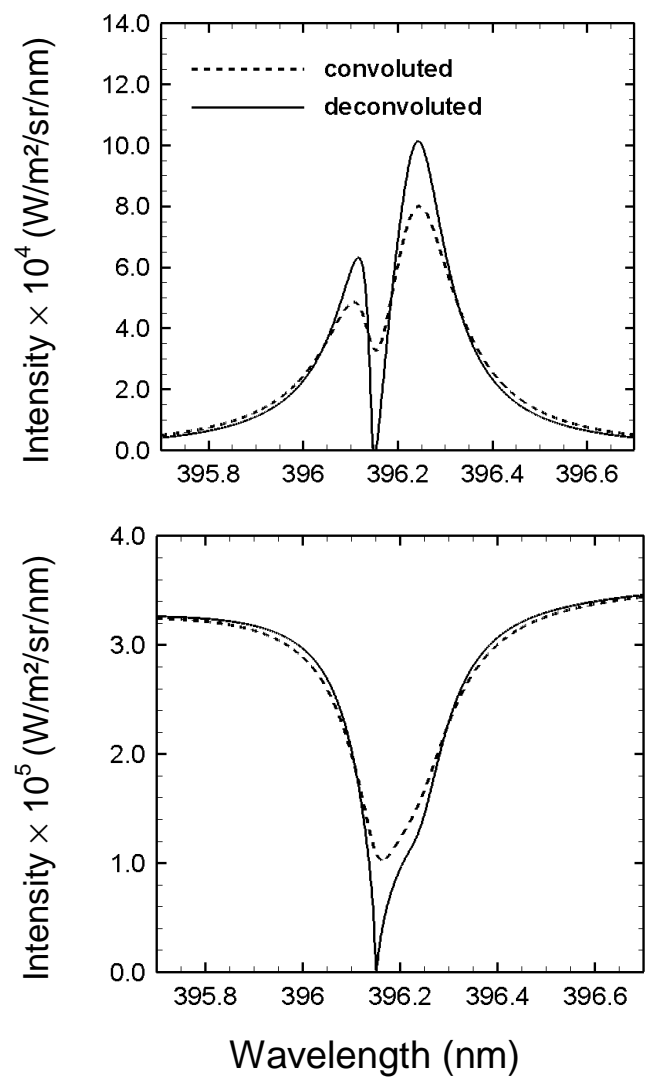

FIG. 8: Convolution by the apparatus function in emission and in absorption. The inlet parameters of the calculation are given in Table I 
The decrease of the electron density when moving from the core to the edge of the plasma induces a monotonous diminution of the Stark shift: therefore, the shape of the spectral profile which results from the integration of the RTE is directly linked to the electron density gradient along the line of sight. According to the assumed Gaussian profiles, the value of this gradient at half maximum is given by:

$$
\left.\frac{d n_{e}}{d x}\right|_{x=\sigma_{e} / 2}=-2 \ln 2 \frac{n_{e 0}}{\sigma_{e}}
$$

The influence of the electron density on the line shape is highlighted in Fig. 9. The calculation is based on the values which are listed in the Table II: at low electron density (less than $10^{23} \mathrm{~m}^{-3}$ ), the profile is centered on the fundamental wavelength of the transition $(396.15 \mathrm{~nm})$ and is almost symmetric. By multiplying the electron density (and consequently its gradient) by a factor of ten, one enlarges highly the profile towards the red. We present in Fig. 10 and 11 the influence of the $n_{10}$ and $n_{40}$ densities on the absorption line shape: an increase of the ground state density broadens the profile without significant increasing of asymmetry and tends to flatten the bottom of the line. The upper state density, the gradient of which is about $10^{4}$ lower than the electron one, takes a negligible part in the shape of the investigated line.

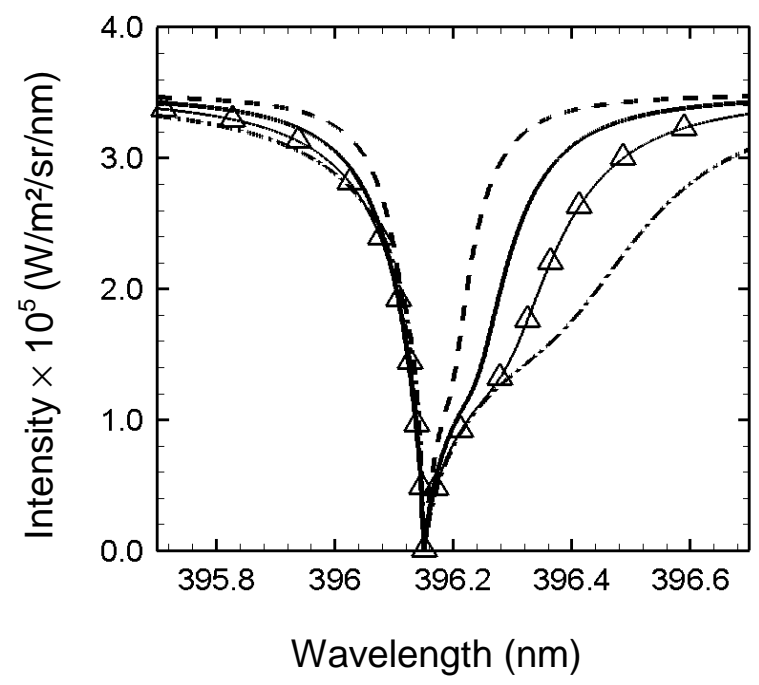

FIG. 9: Influence of the electron density on the $396.15 \mathrm{~nm}$ absorption line profile. Dashed line corresponds to $\mathrm{n}_{\mathrm{e}}=1.0 \times 10^{23} \mathrm{~m}^{-3}$, solid line: $\mathrm{n}_{\mathrm{e}}=2.6 \times 10^{23} \mathrm{~m}^{-3}$, open triangles: $\mathrm{n}_{\mathrm{e}}=5.0 \times 10^{23} \mathrm{~m}^{-3}$, dashed-dot line: $\mathrm{n}_{\mathrm{e}}=1.0 \times 10^{24} \mathrm{~m}^{-3}$.

Summarizing this section, the asymmetry of the recorded absorption profiles are strongly dependent on the electron density gradient at the edge of the plasma plume.

\section{CONCLUSION}

The evolutions in time and space of the species ablated by laser impacts on an aluminum target were obtained by the means of dual-laser photo-absorption spectroscopy. The spectral line profiles were compared with the theoretical spectra derived from the numerical integration of the radiative transfer equation. The widths of the neutral and ionized parts of the ejected vapor were measured, likewise the electron and aluminum densities (resonant and ground states).

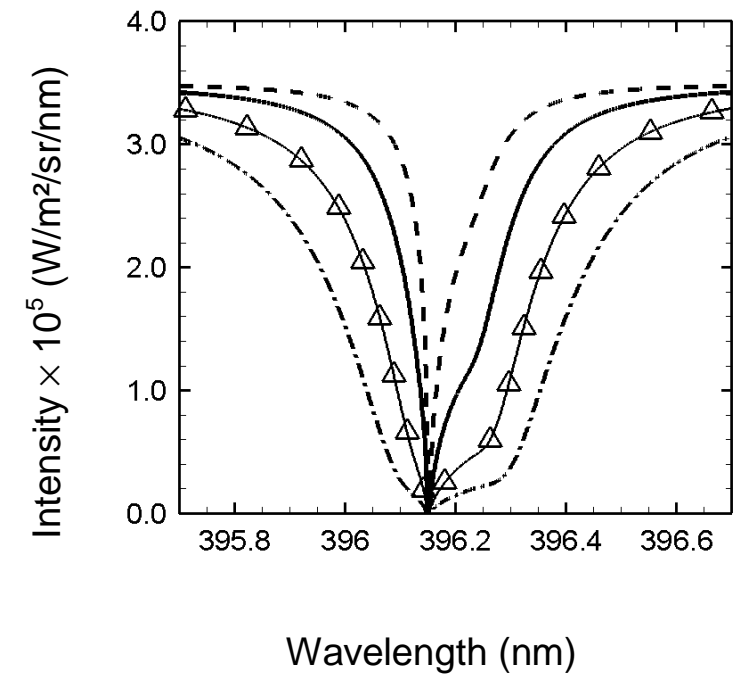

FIG. 10: Influence of the lower level density on the $396.15 \mathrm{~nm}$ absorption line profile. Dashed line corresponds to $\mathrm{n}_{1}=2.5 \times 10^{21} \mathrm{~m}^{-3}$, solid line: $\mathrm{n}_{\mathrm{l}}=4.5 \times 10^{21} \mathrm{~m}^{-3}$, open triangles: $\mathrm{n}_{\mathrm{l}}=1.0 \times 10^{22} \mathrm{~m}^{-3}$, dashed-dot line: $\mathrm{n}_{1}=2.0 \times 10^{22} \mathrm{~m}^{-3}$

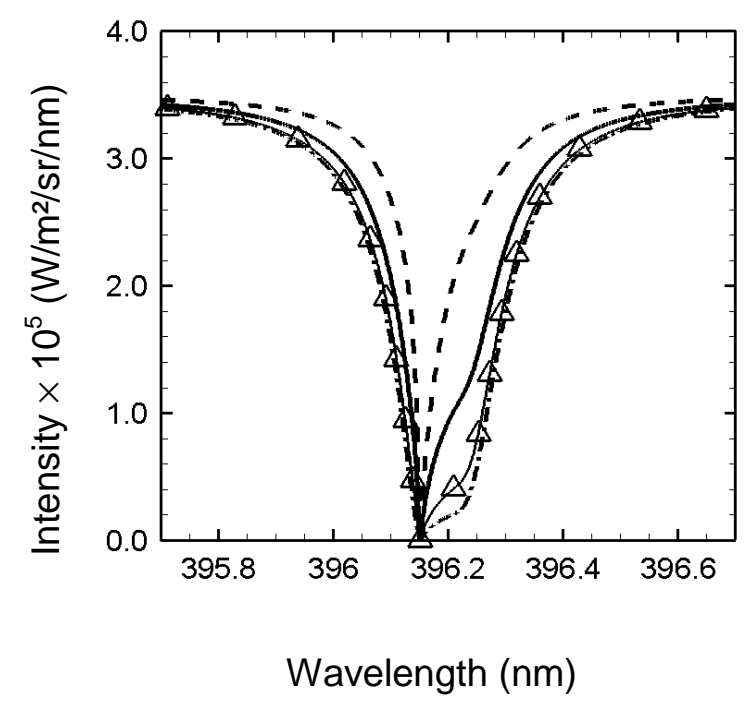

FIG. 11: Influence of the upper level density on the $396.15 \mathrm{~nm}$ absorption line profile. Dashed line corresponds to $n_{u}=5.0 \times 10^{19} \mathrm{~m}^{-3}$, solid line: $\mathrm{n}_{\mathrm{u}}=2.5 \times 10^{19} \mathrm{~m}^{-3}$, open triangles: $\mathrm{n}_{\mathrm{u}}=1.0 \times 10^{19} \mathrm{~m}^{-3}$, dashed-dot line: $\mathrm{n}_{\mathrm{u}}=5.0 \times 10^{18} \mathrm{~m}^{-3}$.

The discrepancy which has been pointed out between the excitation temperatures of the ${ }^{2} S_{1 / 2}$ and ${ }^{2} D_{3 / 2}$ resonant levels reveals that the plasma state is clearly out of equilibrium during the whole investigated time. The characteristic relaxation times of the measured densities, which results from both chemical kinetics and diffusion phenomena have been measured: they ranges between 0.8 and $2.1 \mu \mathrm{s}$. The asymmetric shape of the absorption 
lines has been fairly simulated and directly connected with the value of the electron density gradient at the edge of the plasma. Since absorption and emission experiments have been applied to the same 308.21 and $396.15 \mathrm{~nm}$ $\mathrm{Al}(\mathrm{I})$ transitions within the same laser induced plasma, we have been in position to compare these methods each other: it appears that the former one provides much more reliable results than the classical technique.

By putting into practice such a dual-laser photoabsorption spectroscopy, it is possible to have access to the spatial and temporal evolution of numerous and important characteristics of induced laser plasmas. Owing to its accuracy, this method should bring a new and enhanced support to the validation of the chemical and aerodynamic models devoted to this kind of complicated physical situation.

\section{REFERENCES}

${ }^{1}$ S. Amoruso, R. Bruzzese, N. Spinelli and R. Velotta, J. phys. B: At. Mol. Opt. Phys. 32, R131 (1999).

${ }^{2}$ S. Amoruso, Appl. Phys. A: Mat. Sci. Proc. 69, 323-332 (1999).

${ }^{3}$ Benxin Wu and Yung C. Shin, J. Appl. Phys. 99, 084310 (2006).

${ }^{4}$ R. Rozman, I. Grabec and E. Govekar, Appl. Surf. Sci. 254, 3295 (2008).

${ }^{5}$ Sy-Bor Wen, Xianglei Mao, Ralph Greif and Richard E. Russo, J. Appl. Phys, 101, 023114 (2007).

${ }^{6}$ M. Capitelli, A. Casavola, G. Colonna and A. De Giacomo, Spectrochimica Acta Part B 59, 271 (2004).

${ }^{7}$ G. Colonna, A. Casavola and M. Capitelli, Spectrochimica Acta part B, 56, 567 (2001).

${ }^{8}$ J.R. Ho, C. P. Grigoropoulos and J. A. C. Humphrey, J. Appl. Phys. 79, 7205 (1996).

${ }^{9}$ F. Garrelie, J. Aubreton and A. Catherinot, J. Appl. Phys. 83, 5075 (1998).

${ }^{10}$ T.E. Itina, J. Herman, Ph. Deaporte and M. Sentis, Appl. Surf. Sci. 208-209, 27 (2003)

${ }^{11}$ Rajv K. Singh and J. Narayan, Phys. Rev. B, 41, 8843 (1990).

${ }^{12}$ S. B. Ogale, P. G. Bilurkas, Nitant Mate, S. M. Kanetkar, Nalin Parikh and Bijoy Patnaik, J. Appl. Phys. 72, 3765 (1992).
${ }^{13}$ W. Marine, L. Patrone, B. Luk'Yanchuk and M. Sentis, Appl. Surf. Sci., 154-155, 345 (2000).

${ }^{14}$ T. Donnelly, S. Krishnamurthy, K. Carney, N. McEvoy and J. G. Lunney, Appl. Surf. Sci. 254, 1303 (2007).

${ }^{15}$ V. I. Babushok, F. C. DeLucia Jr, P. J. Dagdigan, M. J. Nusca and A. W. Miziolek, Appl. Opt. 42, 5947 (2003).

${ }^{16}$ G. Colonna, L.D. Pietanza and M. Capitelli, Spectrochimica Acta Part B, 56, 587 (2001).

${ }^{17}$ E. Tognoni, V. Palleschi, M. Corsi and G. Cristoforetti, Spectrochimica Acta Part B 57, 1115 (2002).

${ }^{18}$ J. M. Gomba, C. D'Angelo, D. Bertuccelli and G. Bertuccelli, Spectrochimica Acta Part B 56, 695 (2001).

${ }^{19}$ F. Weritz, S. Ryahi, D. Schaurich, A. Taffe and G. Wilsch, Spectrochimica Acta Part B 60, 1121 (2005).

${ }^{20}$ M. O. Vieitez, J. Hedberg, O. Launila, L. E. Berg, Spectrochimica Acta Part B 60, 920 (2005).

${ }^{21}$ O. Barthélemy, J. Margot, M. Chaker, M. Sabsabi, F. Vidal, T. W. Johnston, S. Laville, B. Le Drogoff, Spectrochimica Acta Part B 60, 905 (2005).

${ }^{22}$ J. Hermann, C. Boulmer-Leborgne and D. Hong, J. Appl. Phys. 83, 691 (1998).

${ }^{23}$ T. Sakka, T. Nakajima, Y. H. Ogata, J. Appl. Phys. 92, 2296 (2002).

${ }^{24}$ H. Furusawa, T. Sakka and Y. H. Ogata, J. Appl. Phys. 96, 975 (2004).

${ }^{25}$ D. Karabourniotis, J. Phys. D: Appl. Phys. 40, 1 (2007).

${ }^{26}$ A. Borghese and S. Merola, Appl. Opt. 37, 3977 (1998).

${ }^{27}$ J. T. Costello, J.-P. Mosnier, E. T. Kennedy, P. K. Carroll and G. O'Sullivan, Phys. Scri. T34, 77 (1991).

${ }^{28}$ E. T. Kennedy, J. T. Costello, J.-P. Mosnier and P. van Kampen, Rad. Phys. and Chem. 70, 291 (2004).

${ }^{29}$ O. Meighan, C. Danson, L. Dardis, C. L. S. Lewis, A. MacPhee, C. McGuinness, R. O'Rourke, W. Shaikh, I. C. E. Turcu and J. T. Costello, J. Phys. B: At. Mol. Phys. 33, 1159 (2000).

${ }^{30}$ H. R. Griem, Plasma Spectroscopy (McGraw-Hill, New York, 1964).

${ }^{31}$ N. Konjevic and M. S. Dimitrijevic, J. Phys. Chem. Ref. Data 13, 619 (1984).

${ }^{32}$ C. Colon, G. Hatem, E. Verdugo, P. Ruiz and J. Campos, J. Appl. Phys. 73, 4752 (1993)

${ }^{33}$ M. Ribière, B.G. Chéron, A. Bultel, ICPIG 2007, Proceedings, 915918.

${ }^{34}$ M. Ribière, B. G. Chéron, A. Bultel, J. H. T. M. P. 12, 111-120 (2008).

${ }^{35}$ J. A. Aguilera, C. Aragon and J. Bengoecha, Appl. Opt. 42 (30) 2003

${ }^{36}$ B. Német and L. Kozma, Spectrochimica Acta Part B 50, 1869 (1995).

${ }^{37}$ S.H. Jeong, R. Grief and R.E. Russo, Appl. Surf. Sci. 127-129, 1029 (1998). 